\title{
Indústria e universidade: a cooperação internacional e institucional e o protagonismo da mobilidade estudantil nos sistemas de inovação da Alemanha
}

Joaquim Carlos Racy'

Everton de Almeida Silva'

\section{Resumo}

0 presente trabalho visa apresentar um quadro sobre as políticas empreendidas pela República Federal da Alemanha no sentido de captar as potencialidades técnico-científicas ao redor do mundo, por meio da atração de estudantes e pesquisadores para as universidades do país, levando em consideração as motivações que originaram tal necessidade para a manutenção de sua competitividade industrial, trespassando percalços e desafios econômicos e sociais percebidos e inserindo tal processo no campo da cooperação internacional. Para tanto, o artigo procurará promover a discussão sobre o papel da universidade no processo de produção de conhecimento e, em seguida, ressaltando a cooperação internacional e interinstitucional como elemento fundamental para a mobilidade estudantil e a produção e troca de conhecimento, buscará situar o processo de migração na Alemanha. A partir disso, estabelecendo relações entre produção de conhecimento e geração de inovação, procurará avaliar como essa realidade se manifesta na competitividade industrial alemã. Assim, além de pesquisa bibliográfica sobre o tema, o artigo estará amparado pelo levantamento dos dados disponíveis que demonstram não só a necessidade da iniciativa, mas como ela vem alterando a disposição e a articulação entre os setores com tal finalidade, buscando avaliar os resultados até então observados. Nesse sentido, serão analisados: a circulação de estudantes do mundo em relação à Alemanha; a participação das áreas privadas, estatais e universitárias em pesquisa e inovação; e os resultados apresentados. 0 período de 2000 a 2012 foi dividido para que se possa delinear a realidade enfrentada pelo país, resultando na implementação do programa. Ainda com base nas informações disponíveis, o artigo procurará delimitar o programa de inovação alemão de maneira a concluir com a indicação de um eventual modelo de geração de inovação passível de reprodução por países em desvantagem em termos de desenvolvimento frente à Alemanha.

\section{Palavras-chave}

I- Pontifícia Universidade Católica de São Paulo, São Paulo, SP, Brasil. Contatos: racjo@uol.com.br; almeida.eas@outlook.com

Cooperação científica - Cooperação interinstitucional - Cooperação internacional - Migração estudantil - Sistema de inovação Internacionalização do ensino superior. 


\title{
Industry and University: international and interinstitutional cooperation and the role of student mobility in the German innovation system
}

\author{
Joaquim Carlos Racy' \\ Everton de Almeida Silva'
}

I- Pontifícia Universidade Católica de São Paulo, São Paulo, SP, Brasil. Contatos: racjo@uol.com.br; almeida.eas@outlook.com

\begin{abstract}
This paper aims to present a framework for policies taken by the Federal Republic of Germany in order to absorb the technical and scientific capabilities worldwide as an effect of the attraction of students and researchers. The motivations, which originated the need for keeping its industrial competitiveness, overcoming mishaps, economic and social challenges as well as introducing this process in the field of international cooperation, will be considered. In order to do so, the article will promote discussion on the role of the university in the process of production of knowledge and highlight the international and interinstitutional cooperation as an important element for student mobility, production and exchange of knowledge, including the situation of the migration process inside Germany. Next, after establishing links between the production of knowledge and generation of innovation, it will demonstrate how this process manifests itself in the German industrial competitiveness. To reinforce the literature on the subject, the paper will provide a survey data that demonstrates not only the need for the initiative, but also how it has been changing the arrangement and the articulation among sectors for this purpose. Finally, the article will analyze: the international circulation of students in relation to Germany: the participation of private, public and university sectors in research and innovation; and their consequences. The period 2000-2012 was divided into two parts to make it possible to delineate the reality faced by the country and the outcome of the program's implementation. Still based on the information available, the article will attempt to delimitate the German innovation program in order to indicate a possible model of innovation that could be reproduced by countries in disadvantage.
\end{abstract}

\section{Keywords}

Scientific cooperation - Interinstitutional cooperation -International cooperation - Student migration - Innovation system Internationalization of higher education. 


\section{Introdução}

A atração de estudantes estrangeiros tem se tornado uma questão de importância ímpar nos debates políticos. Essa agenda ganha ainda mais importância quando se discutem as questões econômicas a ela relacionada, como, por exemplo, a competitividade industrial em um campo de atuação global, haja vista que a geração de novas tecnologias é fundamental para os países, especialmente aqueles que dependem de sua planta industrial para a manutenção de sua capacidade exportadora. Enquanto a integração e o reconhecimento das universidades como parte importante dos sistemas de inovação de um país já é discutida há mais de vinte anos, a necessidade de se aumentar a capacidade de geração de conhecimento nunca foi tão grande. A partir de todo esse imbricado arcabouço econômico, a solução é encontrada em estudantes/ pesquisadores estrangeiros com potencialidades absorvíveis, por meio de um processo de cooperação internacional e interinstitucional.

Atualmente, a Alemanha é um exemplo perfeito de tal situação, quando levamos em consideração sua necessidade industrial, fatores sociais e demográficos, além da atratividade de seu sistema universitário. E, quando deparado com a problemática, o país se inseriu no campo global almejando tanto atrair estudantes e pesquisadores quanto incorporar conhecimentos de países estrangeiros a estudantes e pesquisadores alemães, expatriados. Naturalmente, além de manter sua competitividade, um dos principais objetivos é sustentar sua posição em relação aos EUA e à China, bem como sua liderança econômica e política na União Europeia.

\section{O papel das universidades nos sistemas de inovação}

De acordo com Lundvall (2007, p. 28), o processo de inovação pode ser definido como "a criação de novas combinações de conhecimentos, em processos e produtos almejando o mercado", de maneira incremental ou radical, e está diretamente relacionado ao crescimento econômico. Consoantemente, Nelson e Rosenberg (1993, p. 4), sugerem que o termo deva circundar "práticas, projetos de produtos e processos de fabricação que são novos para eles, se não para o universo, ou mesmo para a nação". Nesse mesmo sentido, para Wixted (2009, p. 23) o progresso econômico e social de um país está crucialmente relacionado à sua capacidade de, "através de negócios e sua população, aprender a acessar o conhecimento atual e entender como transformar dados existentes" com tal finalidade. Para Nelson e Rosenberg (1993, p. 4), as principais motivações para que as empresas se engajem em processos de inovação estão relacionadas às "atividades e [a] os investimentos associados a tornar-se o líder na introdução de um novo produto ou processo, [...] à possibilidade de ficar perto da cabeça do pelotão" e à preocupação com o desempenho econômico, sendo que esses fatores estão intrinsecamente relacionados.

As instituições pertencentes aos sistemas de inovação, definidos por Edquist (2011, p. 2) como "todos os importantes fatores e atores econômicos, sociais, políticos, organizacionais, dentre outros que influenciam o desenvolvimento, difusão e o uso de inovações", focam nos fluxos de conhecimentos em uma sociedade e podem ser distinguidas, principalmente, entre processos de pesquisa e desenvolvimento executados por empresas e aqueles realizados por universidades, institutos e organizações de pesquisas. Paralelamente, Nelson e Rosenberg $(1993$, p. 5) pontuam que o conceito desses sistemas "é de um conjunto de atores institucionais que, em conjunto, assume papel importante em influenciar o desempenho inovador". Nesse sentido, Edquist (2011) afırma que a importância dada ao processo de pesquisa e desenvolvimento realizado por empresas ou outras instituições, como universidades e institutos, é distinta para cada país, embora o relacionamento entre todas as instituições seja crucial.

A importância do relacionamento entre as instituições participantes desse sistema para o progresso tecnológico e desenvolvimento econômico é destacada pela $\mathrm{OECD}$, que afırma: 
0 conceito de sistemas nacionais de inovação se baseia na premissa de que a compreensão das ligações entre os atores envolvidos na inovação é a chave para melhorar o desempenho da tecnologia. Inovação e progresso técnico são o resultado de um conjunto complexo de relações entre atores produzindo, distribuindo e aplicando vários tipos de conhecimento. 0 desempenho inovador de um país depende, em grande medida, de como esses atores se relacionam entre si como elementos de um sistema coletivo de criação de conhecimento e utilização, bem como as tecnologias que utilizam. (OECD, 1997).

Isto porque, como bem destacado pela organização, o progresso tecnológico, oriundo desse relacionamento, não ocorre de maneira linear e sim através dos diversos feedbacks entre essas instituições, as quais podem estar no centro do sistema, atuando no sentido de "organizar a produção e a inovação e a maneira como essas acessam as fontes externas de conhecimento" (OECD, 1997, p. 12). Por outro lado, esse conhecimento é gerado, em grande parte, por “outras empresas, institutos de pesquisas públicos ou privados e universidades" (OECD, 1997) ${ }^{1}$. A partir dessa necessidade de relacionamento, Lange (2013, p. 11) identifica que:

São negociados acordos formais, voluntários, bilaterais ou multilaterais de cooperação entre a universidade e a indústria em pesquisa e desenvolvimento. Eles incluem compromissos de parceiros, atividades e recursos para combinar a transferência de conhecimento para desenvolverem inovações. Os motivos individuais, assim como as modalidades, desses acordos podem ser diferentes.

Por sua vez, Fritsch e Slavtchev (2006, p. 2) e Grossman e Helpman (1989, p. 2)

1- Sobre os aspectos acerca do relacionamento entre empresas e universidades, ver também National Academy of Sciences (2011). afirmam que os papéis das universidades podem ser desempenhados de maneiras diferentes, dependendo do sistema regional de inovação no qual essas estejam inseridas. Isto é, as universidades podem tanto agir no sentido de qualificar e especializar a mão de obra, o que, inevitavelmente, será um canal de transferência de conhecimento para o setor empresarial, quanto através da disseminação de conhecimento científico, técnico e teórico desenvolvido na universidade, por meio de "publicações, seminários, workshops e relacionamentos informais" (LANGE, 2013, p. 11). Lange (2013), adicionalmente, esclarece que esse papel empreendedor das universidades é importantíssimo para o desenvolvimento econômico e pode ocorrer por meio de diferentes funções ou papéis desempenhados. Ozturk (2001, p. 4) ressalta que:

\section{Claramente as disposições educacionais dentro de um determinado país representam um dos principais determinantes da composição e crescimento da produção e das exportações do país e constituem um ingrediente importante na capacidade de um sistema para emprestar tecnologia estrangeira eficazmente.}

No que tange ao segundo ponto abordado por Fritsch e Slavtchev, isto é, a disseminação de conhecimentos científicos por outros meios que não a qualificação de profissionais, Mansfield (1995, p. 55) pontua que "as inovações tecnológicas em várias indústrias têm sido dependentes das pesquisas acadêmicas”. Contudo, é enfatizado por Mansfield (1995, p. 56) que os resultados obtidos pelas empresas por meio de tais pesquisas estão relacionados às “novas descobertas teóricas e empíricas e [aos] novos tipos de instrumentação, que são essenciais para o desenvolvimento de um novo produto ou processo, mas não fornecem a invenção em si”. Tal ponto é aprofundado por Nelson e Rosenberg (1993, p. 7), que sugerem que a ciência e a tecnologia andam juntas e de forma 
intercalada, de modo que, se a ciência gera uma nova tecnologia disruptiva, tal tecnologia gera um novo campo de pesquisa científica, o que, necessariamente, gerará um entrelaçamento entre universidades e empresas no processo de progresso técnico e científico.

Ainda para Nelson e Rosenberg (1993, p. 11), sendo as universidades fontes consideráveis de progresso técnico e científico, em muitos países estas se tornaram os "locais onde a maior parte da pesquisa básica em ciências fundamentais como a física é realizada, embora a dependência de universidades como um locus de pesquisa básica, em contraste com os laboratórios nacionais, varie entre os países”. A importância da pesquisa básica, para os autores, é articulada da seguinte forma:

Embora, ocasionalmente, a pesquisa em ciência básica proporcione entendimentos ou técnicas que levam diretamente aos avanços de produtos ou processos, como foi o caso recentemente em biologia molecular, este não é o habitual. No entanto, mesmo que uma nação só tenha motivos estritamente econômicos no financiamento da investigação universitária, ela não pode se dar o luxo de negligenciar completamente as ciências básicas, uma vez que o treinamento nessas é uma parte essencial da formação nas ciências aplicadas e disciplinas de engenharia. (NELSON; ROSENBERG, 1993, p. 12).

A distinção conceitual entre pesquisa básica e pesquisa aplicada é dada por Stokes (1997, p. 6), que afirma que a pesquisa básica "procura alargar a compreensão dos fenômenos de um campo científico", ao passo que a pesquisa aplicada almeja direcionar o conhecimento científico "para alguma necessidade ou uso individual ou de grupo social”. A partir de um modelo linear, Stokes (1997, p. 11) posiciona esses dois tipos de pesquisa no início do processo, sendo seguidas pela fase de desenvolvimento, isto é, "a fase final na sequência tecnológica”, por meio do qual os conhecimentos serão sistematicamente adaptados para uso e, por fim, a produção, que transformará o conhecimento em um produto.

0 estudo de Mansfield (1995, p. 59) traz evidências consideráveis de que há “um relacionamento direto entre o tamanho dos gastos em P\&D nas universidades e sua contribuição percebida à inovação industrial”. Adicionalmente, em seu estudo sobre o impacto das pesquisas acadêmicas sobre a performance industrial em cinco diferentes tipos de indústrias, a National Academy of Sciences (2011) chega à conclusão de que esse impacto difere de indústria para indústria e, para que haja um resultado satisfatório oriundo desse relacionamento, muitas vezes são necessários relacionamentos de longo prazo. Isto porque, para a National Academy of Sciences (2011, p. 205), “cada indústria ilustra um padrão único de colaboração de pesquisa indústria-universidade e maneiras diferentes pelas quais as contribuições acadêmicas são usadas". Além disso, a pesquisa sugere que as contribuições acadêmicas à performance industrial vão além da geração de novos produtos, tecnologias ou serviços comercializáveis, isto é, fogem da esfera comercial.

Outro ponto importante a se ressaltar é a relação locacional entre empresas e universidades. Thursby e Thursby (2006) discutem que, quando uma empresa pensa sobre a localização de uma planta, há que se destacar a proximidade com universidades. $\mathrm{Na}$ pesquisa desenvolvida pelos autores, por meio de escala de importância, os pontos relacionados à proximidade com universidades ficaram na quarta e na quinta posição. A proximidade com universidades também é abordada no estudo de Abramovsky, Harrison and Simpson (2006). Os autores identificam, entretanto, que há variações quanto à relação de proximidade entre empresas e universidades; enquanto as evidências são significativamente mais fortes para as indústrias farmacêutica e química, por exemplo, elas tendem a diminuir para outros setores empresarias. 


\section{O contexto da migração de estudantes}

Contextualizando as implicações do movimento neoliberal ${ }^{2}$, Brooks e Waters (2011, p. 7) pontuam que, apesar de sempre ter existido uma predisposição à migração, o número tem crescido abruptamente nos últimos anos. Para as autoras, avanços de ordem tecnológica e de transporte representaram "um impacto significativo sobre a inclinação das pessoas e sua capacidade de se mover". Rizvi (apud BROOKS; WATERS, 2011, p. 7) argumenta que tais movimentos tiveram implicações substanciais para a educação ao redor do mundo, principalmente no que tange à pesquisa acadêmica, pois os campos de pesquisa não estão mais limitados geograficamente.

Para Maringe (2010, p. 24) a intensificação da globalização nas últimas décadas, que influenciou inúmeras organizações e instituições, também apresentou novos desafios para as universidades, de forma que essas "voltaram-se para a internacionalização, tanto como uma resposta e uma forma proativa de atender às demandas da maior globalização, quanto uma imediata forma de preparação para futuros previstos".

A cooperação internacional aparece então como importante elemento para a compreensão e equalização do processo. Nesse sentido, a partir da Segunda Guerra Mundial, acordos internacionais motivados por variadas questões relativas à segurança e ao desenvolvimento vêm se realizando com desenhos bastante diversos. A dinâmica das relações internacionais, que tem se alterado ao longo da história contemporânea, levando inclusive à globalização, viria a sinalizar uma séria mudança do papel protagonizado pelos estados nacionais enquanto atores centrais do sistema.

Nessa perspectiva é que se deu a formação do sistema multilateral, a partir da criação da ONU, que, com caráter supranacional, teria por objetivo reordenar as relações internacionais, constituindo processos cooperativos que iriam

2- Sobre o posicionamento das autoras, ver também Maringe (2010). além daqueles realizados tradicionalmente à margem entre estados nacionais e tendo como motivo suas razões excludentes.

Assim, a manifestação de múltiplos interesses e, principalmente, de insatisfações de diferentes e novos atores no cenário internacional, aumentando a interdependência sistêmica internacional e levando a uma redução da capacidade dos estados de tomarem decisões individuais e exclusivas, uma vez que tais decisões não aufeririam uma necessária maximização de ganhos ou uma minimização de perdas, geraria acordos baseados em ações conjuntas com diferentes recortes, promovidas por atores de matizes distintos na busca da promoção da estabilidade internacional com amparo na ideia de cooperação.

Com o desenvolvimento desse quadro, novas formas de atuação cooperativa se desenvolveriam, pois, mesmo dentro da nova ordem de relacionamentos proposta com a constituição da ONU, tremendas ambiguidades continuariam a se manifestar no sistema internacional. Não há como não considerar, nesse sentido, que a manutenção do desejo de conquista de condições superiores de vida material pelas sociedades ainda depende em grande parte das ações de estado, na medida em que este, mesmo com uma perda relativa de autonomia, se coloque como elemento básico para a aglutinação dos interesses dos indivíduos, expressos num sentimento nacional.

Mas o que é mais importante, na realidade, é que a efetividade dos arranjos de cooperação internacional deve se dar pelo fato de corresponderem à necessidade de superação de problemas muitas vezes universalmente compartilhados. E a nova conformação da sociedade internacional, sendo esta agora gravitada por uma nova plêiade de atores, tais como as organizações não governamentais e também o estado, confere às ações de cooperação um sem-número de possibilidades.

Historicamente, pode-se dizer que a cooperação internacional começou a tomar corpo no fim da Segunda Guerra Mundial, mas, 
em função do desenvolvimento do sistema internacional, começou a se institucionalizar a partir dos anos 1960 e se desenvolveu segundo duas perspectivas distintas ${ }^{3}$.

A primeira assumia um caráter assistencialista e previa ações desenvolvidas por estados ricos, visando ajudar estados pobres na superação de problemas básicos de desenvolvimento, e a segunda, desenvolvida com base nos resultados auferidos com a primeira, se baseava na lógica que sustentava a criação da ONU e que viria a promover a instituição de um aparato jurídico que tinha por fim a efetivação de projetos voltados, de fato, para o desenvolvimento de países mais pobres. Para tanto, inclusive, receberia a denominação de cooperação técnica internacional, subordinada a regras e normas emanadas por um organismo específico da ONU, o PNUD - Programa das Nações Unidas para o Desenvolvimento. Isso, por um lado, garantia à cooperação o alcance de fins almejados, mas, por outro, criava restrições de ordem burocrática e financeira que reduziam o escopo da cooperação realizada e, por consequência, de seus resultados.

Contudo, ainda que conservando a condição básica de uma relação de doação e recepção de conhecimento, essa cooperação, incorporando a noção de reciprocidade, considerava que o desenvolvimento compreende uma série de elementos que não são de propriedade exclusiva de um país e que, por isso, a relação em questão trata de operação conjunta que visa oferecer ganhos compartilhados e mudar o eixo do processo.

Assim também e nessa mesma medida, a concepção de cooperação pela transferência de recursos passou por um processo de ampliação, estendendo-se às áreas de conhecimento em ciência e tecnologia, consolidando a ideia de que nenhuma atividade de cooperação pode ser situada num quadro em que existem fornecedores ou recebedores exclusivos, ou países ricos e detentores exclusivos de conhecimento, pois o conhecimento deve ser considerado o fruto

\section{3- Ver Racy (2007).}

de uma operação de construção em parceria e promovida por um sem-número de organizações. E aqui se define a importância que assumem as organizações de caráter não estatal no processo.

E é nessa perspectiva que se coloca o processo de intercâmbio acadêmico e científico como resultado de arranjos entre atores como a própria universidade, a indústria e, mesmo, o Estado. Além disso, o que se percebe é que, sendo uma operação de reciprocidade, a cooperação nesse campo pode gerar uma inversão de processo, isto é, um país tradicionalmente fornecedor de recursos, no caso o conhecimento, pode se transformar num recebedor do mesmo.

Segundo a OECD (2002), apesar de ser um movimento relativamente novo, a migração de estudantes tem ganhado importância nos últimos anos, principalmente no nível de ensino superior. Para o autor, tal movimento se dá por uma série de fatores que agem de maneira congruente, dentre os quais podem ser destacados a oferta restrita de cursos por parte de instituições locais, especialmente em países em desenvolvimento; o interesse dos estudantes em se desenvolver culturalmente em outro país; a queda dos custos de viagem e manutenção em outro país; vantagens econômicas e culturais das instituições que recepcionam os alunos; e interesses governamentais em promover tanto a expatriação de estudantes nacionais quanto a recepção de estudantes estrangeiros.

Não obstante, Brooks e Waters (2011, p. 2) colocam a questão nesse mesmo sentido, sugerindo, a título de exemplo, que, apesar de estar crescendo o número de estudantes estrangeiros oriundos da Índia e China em universidades de todas as partes do mundo, esses países "também têm investido pesadamente em seus próprios sistemas de ensino superior, em uma tentativa explícita de aumentar a sua atratividade para o mercado internacional de estudantes".

Os investimentos para atrair estudantes estrangeiros estão ligados a uma ampla gama de motivações, segundo Maringe (2010, p. 27), em que se deve incluir: 
A relevância cultural de aprendizagem internacional; a necessidade de contribuir para a evolução das necessidades globais do mercado de trabalho; a crescente importância da aprendizagem internacional e comparativa num mundo globalizado; a necessidade de reformulação de currículos para enfrentar novos desafios em um mundo globalizado e a importância de reconstruir os modelos ocidentais de conhecimento e compreensão, a fim de acomodar outros modelos de diferentes partes do mundo.

Brooks e Waters (2011, p. 136), além de destacarem o abrupto aumento de pesquisas relacionadas à internacionalização do ensino superior, ultimamente, consideram que essa situação "está ocupando um lugar importante na agenda dos formuladores de políticas em todo o mundo". Dado isto, Montsios (2009 apud BROOKS; WATERS, 2011) sugere que, além da transnacionalização da formulação de políticas, há "a total submissão da educação às atividades da economia global”, muito embora, esta não seja a única esfera a se analisar, levando-se em consideração, também, conforme mencionado por Maringe (2010), fatores sociais e culturais que exercem influência na formulação dessas políticas, sendo que:

Ao explicar as diferenças por país de destino, também é útil considerar as maneiras pelas quais os governos anfitriões buscaram comercializar seu ensino superior para estudantes estrangeiros, e para examinar o impacto que isso teve sobre os fluxos de estudantes. (BROOKS; WATERS, 2011).

A argumentação de Taylor (2010), por sua vez, leva em conta as vantagens percebidas pelos governos na atração de estudantes estrangeiros, que vão muito além das vantagens financeiras. Para o autor:

No entanto, os benefícios percebidos são muito mais amplos, com esses alunos, muitas vezes, preenchendo as lacunas de competências nos mercados de trabalho locais ou nacionais e também oferecendo a perspectiva de longo prazo de laços comerciais mais estreitos com o país em questão. Os estudantes internacionais, e as ligações que mantêm com os países onde eles obtêm a sua formação superior, oferecem aos governos uma rota por meio da qual é possível estender sua influência internacional. (TAYLOR, 2010, p. 86).

Nota-se então que o principal contraste entre a migração de estudantes no passado e o movimento que se vivencia atualmente, de acordo com Brooks e Waters (2011, p. 22), "está associado com a formulação de políticas significativas e explícitas - nos níveis nacional, regional e internacional". Isso porque, para as autoras, as políticas não são mais determinadas no nível do estado-nação, mas em um contexto global, levando em consideração várias organizações altamente influentes.

A partir desse ponto de vista, Maringe (2010, p. 22) sugere que "há sempre alguém no controle das decisões mais importantes", inclusive no campo da educação superior, no qual se podem encontrar inúmeras instituições e organismos internacionais tanto no sentido de incentivar a mobilidade estudantil, como no de supervisionar a qualidade do ensino. Referidas organizações, naturalmente, possuem distintas funções no que tange ao incentivo da internacionalização do ensino superior. No que se refere ao incentivo desse tipo de mobilidade, é destacável o papel desempenhado pelo Banco Mundial, pela OECD, pela Unesco e, mais especificamente na Europa, pela Comissão Europeia, por meio dos programas Erasmus e Erasmus Mundus. Já no que tange ao monitoramento desse movimento, dentre outros, os autores mencionam o Conselho de Acreditação do Ensino Superior (Council for Higher Education Accreditation - CHEA), o Consórcio para Financiamento do Ensino Superior (Consortium on Financing Higher Education - COFHE), o Centro de Controle de Qualidade em Educação Internacional (Centre for Quality Assurance in International Education 
- CQAIE) e a Associação das Universidades da União Europeia (Association of European Union Universities - AEUU).

Outro ponto intensamente abordado é a questão da evasão de cérebros (brain drain). Segundo Brooks e Waters (2011, p. 143), tratamse das "perdas sofridas por nações que mandam um número considerável de estudantes para o exterior". De acordo com as autoras, embora seja constantemente sugerido por vários estudiosos que tal situação possa gerar um problema para países em desenvolvimento, não há evidências consideráveis que sustentem tal argumentação. Nesse sentido, as autoras lançam mão do termo circulação de cérebros (brain circulation), que se refere ao cômputo final gerado pelo processo de brain drain e a sua contrapartida, o brain gain, isto é, as vantagens recebidas pela nação.

Taylor (2010, p. 90), entretanto, reconhece que há um risco inerente ao processo e que tal movimento deve ser debatido em face da tensão que é gerada, geralmente, entre países desenvolvidos e em desenvolvimento, uma vez que:

Os governos que procuram desenvolver suas próprias instituições nacionais de ensino superior, a fim de atender às necessidades nacionais de habilidades e conhecimentos, e para trazer impacto nacional sobre a economia do conhecimento, deve se preocupar com a "evasão de cérebros". Os estudantes vão estudar no exterior, muitos dos quais não podem retornar.

\section{A inovação como fator de competitividade industrial da Alemanha}

A relação umbilical que a Alemanha mantém com sua indústria já passou por inúmeras provações ao longo do século $\mathrm{XX}$. Entretanto, no início do século XXI, a Alemanha, assim como muitos outros países, se deparou com uma questão vital para a competitividade e a manutenção de sua indústria: a inovação.

Para Hübner (2009, p. 144), a relação entre o processo de geração de inovação e o de- senvolvimento do capitalismo apresenta variações. 0 autor pontua que, embora a inovação desempenhe um papel essencial no "crescimento econômico, mudança estruturada e modernização", as variações do sistema capitalista de uma economia influenciarão o processo de geração da inovação tecnológica. Exemplificando essas variações, Hübner (2009, p. 146) ressalta que enquadraria a Alemanha, assim como Itália e Suécia, como uma variação "corporativa do capitalismo", na qual o sistema é identificado pela "integração de grupos de interesses sociais à gestão do processo de acumulação". Para Hübner (2009, p. 152), enquanto as variações capitalistas mais liberais (orientadas para o mercado) tendem a possuir mecanismos concorrenciais que acabam por influenciar e em certa medida determinar a progressão científica, a variação alemã é "o tipo continental europeu ideal de inovação e regime de produção", em que o processo de inovação é determinado por "dominantes universidades públicas, organizações de pesquisa, população homogeneamente qualificada, regime salarial legalizado", além de "processos inovadores gradualistas".

A problemática da inovação gradualista, ou incremental é, segundo Glassman (2009), uma característica das empresas alemãs. Segundo o autor, isso implica uma dificuldade dessas empresas em se envolver em novas tecnologias (inovação disruptiva ou radical) e está relacionada aos traços característicos de seu modelo industrial, como a relação contratual entre as empresas, entre os bancos e a orientação para as partes interessadas no negócio. Tal realidade começou a mudar apenas em 1997, dada a reestruturação do modelo e mudanças na política do Mittelstand alinhadas à participação do governo no financiamento de pesquisa e desenvolvimento.

Aqui parece ficar clara a matriz de cooperação que se estabelece entre as instituições alemãs na formulação da política nacional de desenvolvimento econômico e que se reflete nas relações externas do país no campo da cooperação internacional, residindo nisto a importância de seu estudo. 
Notadamente, nesse cenário, no qual a participação do governo escapa da esfera regulatória do mercado, a interação público-privada se dá, fundamentalmente, com o objetivo de estimular o avanço da fronteira tecnológica, mitigando os riscos do setor privado: a esfera pública passa a ter papel determinante. Atualmente, por ser um país extremamente dependente de sua planta industrial, a qual lhe confere a posição de terceiro maior exportador do mundo, o processo de pesquisa e desenvolvimento é vital para a manutenção de seus índices de competitividade.
Nota-se que, apesar de as exportações do país terem mais do que dobrado de 2000 a 2011 (acréscimo de 114\%), a proporção dos produtos de alta tecnologia dentro das exportações do país vinha diminuindo em média 3,9\% ao ano de 1999 a 2008, segundo dados do Banco Mundial (Gráfico 1). Os investimentos em P\&D em relação ao PIB do país, segundo tais dados, atingem um valor de 2,84\%, e vinham apresentando evolução média de $0,35 \%$ de 2000 a 2007, passando posteriormente a uma variação média de 2,97\% de 2008 a 2011.

Gráfico 1 - Exportações de produtos intensivos em tecnologia

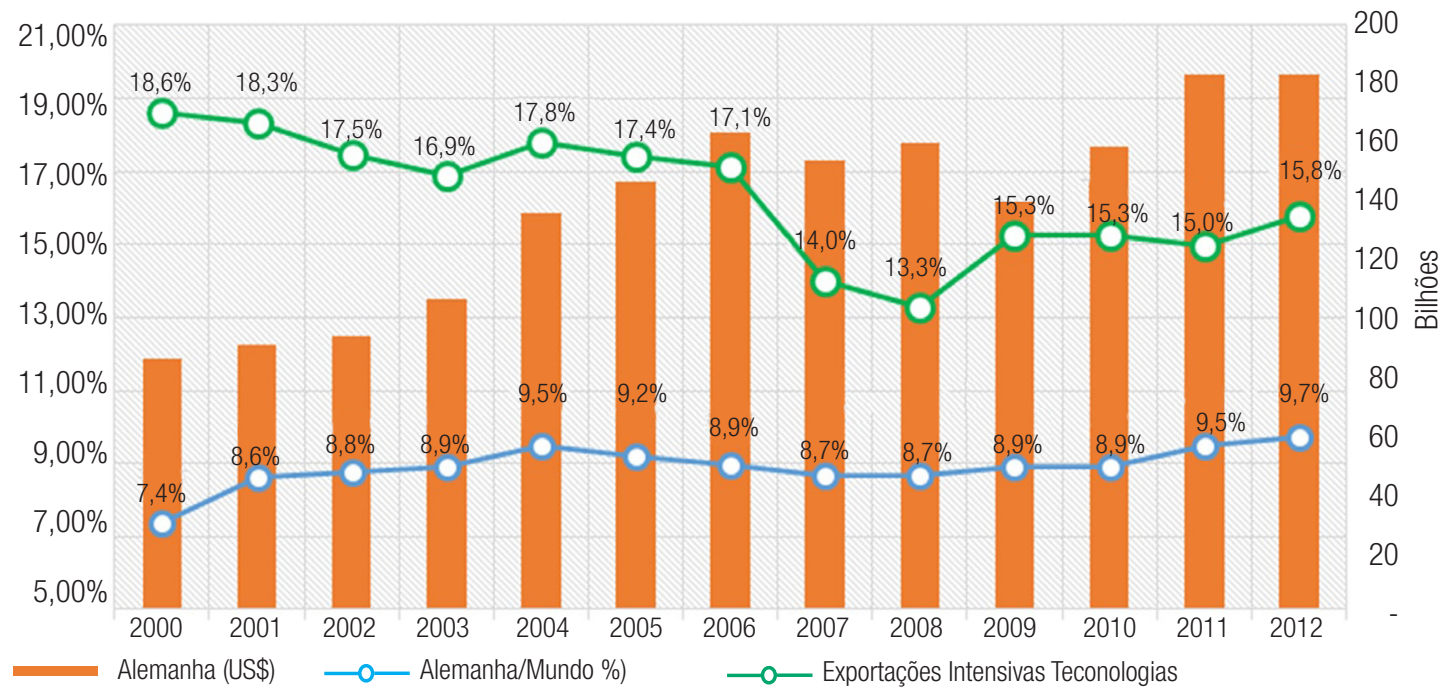

Fonte: World Bank

*Refere-se à série High-technology exports (TX.VAL.TECH.CD).

Nesse sentido, é interessante observar que, no que tange à localização do processo de geração de inovação no país, há um relativo equilíbrio em sua distribuição regional, naturalmente com alguma concentração em regiões economicamente mais ativas (BadenWürttemberg, Bayern e Hessen - com valores acima da média do país). De acordo com dados do DeStatis ${ }^{4}$, separando os investimentos em relação ao PIB em três origens distintas

4- Refere-se à série Wissenschafts- und Technologieindikatoren für Deutschland und die Bundesländer, disponivel em https://www.govdata.de/ web/guest/daten/-/details/destatis-service-91211-0001-test-test. (setor privado, setor estatal e universidades), nota-se que o setor privado realizou em 2009, em média, 67,5\% dos investimentos totais e, embora haja uma correlação positiva entre o aumento de investimentos nos três setores, podem-se destacar regiões nas quais o setor privado toma iniciativas mais contidas, sendo os investimentos contrabalanceados pelo setor estatal ou universitário, como, por exemplo, Berlin, Saarland, Bremen e, principalmente, Branderburg, onde a porcentagem dos investimentos em P\&D pelas universidades se iguala à da iniciativa privada. 
Cabe destacar, ademais, que as regiões onde as universidades concentram a destinação de parcela do PIB à P\&D são Berlin (0,93\%), Bremen $(0,71 \%)$, Thüringen $(0,56 \%)$, BadenWürttemberg (0,54\%), Hessen (0,53\%) e Hamburg (0,51\%), isto é, regiões onde grandes empresas que demandam inovações tecnológicas estão sediadas e que contam com universidades tradicionais ${ }^{5}$. Stuttgart, situada na região de Baden-Württemberg, por exemplo, é a cidade com o maior número de patentes do país, segundo dados da $\mathrm{OECD}^{6}$; Starkenburg (Hessen) e Berlin são outros bons exemplos. Bayern é outro exemplo bem parecido com o caso anterior, diferindo apenas no fato de que os registros de patentes estão mais concentrados em München. Não obstante, segundo dados da Unesco Institute for Statistics ${ }^{7}$, observa-se que, enquanto os investimentos absolutos em moeda local oriundos do setor privado apresentaram crescimento de 13\% de 2008 a 2012, os investimentos do setor estatal chegaram a $23 \%$ e os realizados pelas universidades a surpreendentes $28,2 \%$ no mesmo período.

Um problema para o país, entretanto, parecer ser a quantidade de pesquisadores e estudantes. Comparando diretamente a proporção do PIB do país destinada à $\mathrm{P} \& \mathrm{D}$, a Alemanha se encontra nas primeiras posições, rivalizando com as economias fino-escandinavas (Finlândia, Noruega, Suécia e Dinamarca), as quais também são conhecidas pelo desempenho tecnológico. Entretanto, quando analisados os dados relativos às quantidades de pesquisadores, nota-se que este número por milhão de habitantes é menor do que o de

5- Para o caso específico de Berlin, embora a cidade mereça um exame mais detalhado, pode-se pontuar brevemente que a região vem buscando atrair empresas de tecnologia de informação, especialmente ainda em estágio embrionário, e conta com renomadas universidades no campo de tecnologia (destacam-se Freie Universität Berlin e Technische Universität Berlin), o que justificaria o relativamente alto investimento, sob a ótica de consolidação de um sistema de inovação.

6- A série se refere à Patents by regions (Patent office: Patent application to the EPO / Reference region: Inventor(s)'s country(ies) of residence).

7- A série estudada é o GERD (Gross Expenditure on Research and Development) e se refere a preços constantes. A instituição utiliza rigorosamente a mesma distinção categórica do DeStatis (setor privado, estatal e universidades), adicionando a categoria "privada sem fins lucrativos". países como Áustria, Portugal e Luxemburgo, podendo ser comparado com Eslovênia, Bélgica e Irlanda. Finlândia e Dinamarca, países com maior número de pesquisadores por milhão de habitantes, possuem 1,8 e 1,6 vezes a quantidade de pesquisadores da Alemanha. A quantidade de matrículas no ensino superior poderia ser uma explicação para tanto. Embora as séries disponiveis sugiram isto, ao se considerarem as questões demográficas, os dados não são suficientes para se chegar a uma conclusão.

\section{A geração de conhecimento por meio da migração de estudantes:} o programa alemão

Segundo estimativas do ministério da educação e pesquisa do país, mais de 90\% do conhecimento mundial é gerado fora da Alemanha, e, nesse sentido, a ideia é, fundamentalmente, utilizar esse conhecimento em benefício do país. A estratégia do governo federal alemão para a internacionalização da ciência e pesquisa, aprovada em 2008, aborda questões fundamentais para que a Alemanha mantenha e desenvolva sua competitividade tecnológica por meio do processo de aprofundamento e progresso da cooperação científica entre nações do mundo e da União Europeia, dando especial atenção para os países em desenvolvimento. Referido planejamento tem por objetivo alcançar quatro metas, quais sejam: (i) reforçar a cooperação de pesquisa com líderes mundiais em pesquisa e desenvolvimento; (ii) exploração internacional dos potenciais inovadores; (iii) intensificar a cooperação com os países em desenvolvimento em longo prazo; e (iv) assumir responsabilidade internacional e controlar os desafios globais.

De acordo com o documento, a competição global pelos "melhores cérebros" requer maiores esforços e, principalmente, investimentos. Assim sendo, os investimentos da Alemanha em pesquisa e desenvolvimento foram alinhados aos da União Europeia, definidos em $3 \%$ do produto interno bruto do país, apesar de 
serem reconhecidas as adversidades econômicas de se manter tal taxa. 0 valor, que representa um aumento de 0,5\% na média dos investimentos de 2000 a 2008, quando a proposta foi aprovada, demonstra uma preocupação do país com as taxas irregulares apresentadas tanto pelo país quanto pela União Europeia, em uma economia global na qual a Alemanha já não compete mais apenas com EUA e Japão pelos mercados importadores globais, mas também com China, Coreia do Sul e Índia ${ }^{8}$.

0 documento identifica que, para tanto, será necessário oferecer aos pesquisadores alemães a oportunidade de cooperar com os melhores cientistas de todo o mundo, além da necessidade de internacionalizar os centros de formação do país, promovendo o ensino superior e os processos de pesquisa e inovação do país. Ao mesmo tempo, as empresas, segundo o documento (2008, p. 3), devem "criar centros de excelência que agem como ímãs para estudantes, cientistas e empresas de todo o mundo". É reconhecido, assim, que, enquanto os estudantes estão em busca de grupos e instituições de excelência em sua área de pesquisa, essas instituições e grupos buscam por eles. Assim sendo, as duas dimensões da agenda de migração de estudantes da Alemanha requerem a coordenação dos organismos nacionais que cuidam de tal questão, quais sejam: o Serviço Alemão de Intercâmbio Acadêmico (DAAD Deutscher Akademischer Austauschdienst) e a Fundação Alexander von Humboldt. Além disso, destaca-se, nesse processo, a cooperação e mobilidade de estudantes dentro da própria União Europeia, por meio dos programas Erasmus e Erasmus Mundus.

Em todo esse trabalho, o papel do DAAD e da Fundação Alexander von Humboldt são fundamentais. Analisando apenas os números de estudantes estrangeiros na Alemanha, podese facilmente concluir que a campanha Study in Germany: Land of Ideas, realizada em todos

8- Importante notar que a competição entre esses países não se limita aos mercados importadores, mas refere-se, também, à competição pelos próprios estudantes, haja vista que, conforme indicado, os países emergentes têm atentado para tal questão. os cincos continentes pelo DAAD, alcançou resultados incríveis desde a data de seu lançamento, em 2008. Já entre 2008 e 2009, o número de estudantes estrangeiros amparados pelo DAAD cresceu 15,2\% graças ao aumento de quase cinquenta milhões de euros em seu orçamento, que representou um crescimento de 14,5\% comparado ao ano anterior. Em 2012, quando foi publicado o último relatório anual, seu orçamento era da ordem de 407,4 milhões de euros, sendo os maiores financiadores do instituto o Ministério de Relações Exteriores (44\%) e o de Educação e Pesquisa (24\%) ${ }^{9}$.

A maioria dos estudantes estrangeiros amparados pelas bolsas do DAAD ainda são da Europa Central e Oriental, justamente onde a instituição mantém mais escritórios e centros de informações. A proporção, que era da ordem de $51,8 \%$, vem diminuindo anualmente, devido ao aumento do número de estudantes do norte da África, do Oriente Médio, da África Subsaariana e da Europa Ocidental, segundo a classificação elaborada pela instituição. Entretanto, cabe ressaltar que, em números absolutos, o número de estudantes da Europa Central e Oriental não apresentou diminuição significativa (2,3\%). Algo destacável é que, apesar de todos os esforços, a proporção de estudantes da América do Norte ainda é pequena (4,5\%), o que sugere que esses estudantes têm preferido outros caminhos. A preocupação da Alemanha está justamente na perda do potencial que poderia ser agregado ao país com o concurso desses estudantes, levando em consideração a qualidade de ensino de EUA e Canadá. Assim sendo, o aumento de 80,5\% no número de bolsistas alemães que partiram para a América do Norte é justificável.

Por sua vez, a Fundação Alexander von Humboldt parece, neste ponto exclusivamente, ter uma atuação mais limitada em escopo do que a do DAAD, mas tão importante quanto. Ressalta-se aqui que um dos pontos estratégicos da fundação é fortalecer o desenvolvimento de pesquisas e pesquisadores

9- 0 s relatórios anuais do DAAD podem ser acessados em https://www. daad.de/medien-und-publikationen/en/29887-annual-report/ 
na Alemanha, conectando o país à elite acadêmica mundial, fomentando a pesquisa científica internacional, inclusive conferindo premiação aos pesquisadores. Analisando os dados disponibilizados ${ }^{10}$, percebe-se que 0 número de bolsas concedidas vinha diminuindo até 2010. Tal situação se reverteu em 2011, enquanto o número de candidaturas apresentou pouca variação. A proporção dos estudantes e pesquisadores europeus é parecida com a do DAAD, sendo que 39\% são oriundos da Europa Central e Oriental, seguidos pelos asiáticos. A grande distinção em relação à composição do corpo de bolsistas do DAAD diz respeito aos pesquisadores da América do Norte, pois cerca de 23,3\% dos bolsistas vêm dos EUA e do Canadá e, além disso, os alunos e pesquisadores dos EUA estão entre os que mais se candidatam.

Partindo da medida segundo a qual, depois de um período de sucessíveis acréscimos, o número de estudantes estrangeiros no país chegou a 10\%, almeja-se aumentar essa proporção por meio da promoção dos programas de mestrado e doutorado. Ao mesmo tempo, o documento (2008, p. 16) ressalta que tais estudantes devem estar "aptos a aplicar suas habilidades na Alemanha, mesmo depois de terem completado seus estudos", tendo sido o sistema legal adaptado para a permanência destes no país depois de findos os estudos, uma vez que se deseja que esses estudantes encontrem empregos nos quais possam aplicar as habilidades adquiridas. Além disso, foi criado um grupo com o objetivo de amparar alemães no exterior que desejem retornar ao país ${ }^{11}$. Naturalmente, são reconhecidas as consequências econômicas para os países em desenvolvimento que tal política pode ocasionar, devido à evasão de habilidades (brain drain) ${ }^{12}$. 0 documento ressalta

10- Os dados se referem aos programas Alexander von Humboldt, George Forster e Feodor Lynen e podem ser acessados em http://www. humboldt-foundation.de/web/statistics.html

11- Services provided by the Federal Office of Administration relating to Germans willing to return to Germany.

12 - Apesar de um ponto importante do planejamento ser o incentivo aos alunos e pesquisadores alemães irem estudar no exterior, é pontuado que os programas devem oferecer atrativas oportunidades de retorno para esses estudantes, de modo a evitar o mesmo problema de evasão de cérebros, que tal processo deve ser evitado por meio de mecanismos que possibilitem a circulação de cérebros entre países. Além dos estudantes estrangeiros, cabe pontuar que se almeja também aumentar o número de professores e pesquisadores estrangeiros nas universidades e institutos de pesquisas alemãs.

A cooperação com países em desenvolvimento, de acordo com o documento, terá um papel importante, replicando o diálogo mantido com a China. Segundo o planejamento, a provisão de formação moderna para executivos e pessoal especializado é essencial para o contínuo e sustentável desenvolvimento desses países, além de oferecer maior capacidade para esses profissionais coordenarem e aprofundarem as relações cooperativas entre países. Neste sentido, busca-se ir além das áreas de formação em engenharia e ciências naturais, incluindo também as ciências humanas e sociais, como forma de contribuir para o desenvolvimento desses países. Para tanto, objetiva-se incentivar universidades e institutos de pesquisas a atrair estudantes desses países, garantindo que esses continuem a se adequar às questões globais e aos problemas dos países em desenvolvimento. Analisando dados do DAAD, observa-se significativo acréscimo no número de estudantes da Ásia e Pacífico (18,9\%), África Subsaariana $(28,6 \%)$ e norte da África e Oriente Médio (80,9\%). Apesar de este número ter diminuído para a América Latina - e apenas para ela - numa porcentagem de $26 \%$, o número de bolsistas alemães nesta região foi o que teve maior aumento (153,3\%).

Utilizando os dados do Banco Mundial referentes à publicação de $\operatorname{artigos}^{13}$ como uma proxy para se mensurar os resultados acadêmicos de todo este movimento para o país, pode-se notar que, enquanto o número de publicações vinha aumentando de maneira irregular de 2000 a 2007, (média de $0,31 \%)^{14}$, a relação entre publicações na Alemanha frente à União Europeia

principalmente para os EUA, o que, aliás, como apontado pelo documento, já vinha e vem acontecendo entre doutores alemães que estudam nos EUA. 13- Refere-se à série Scientific and technical journal articles (IP.JRN.ARTC.SC). 14- É notável, também, os excepcionais aumentos verificados em 2004 $(1,84 \%)$ e $2005(2,74 \%)$ em relação aos anos anteriores, que acabam sendo absorvidos pela média. 
apresentava um desempenho significativamente menor, o que não é completamente explicado pelo alargamento da União Europeia no ano de $2004^{15}$. 0 que realmente chama atenção no período de 2000 a 2007 é o aumento de publicações na Holanda (15\%) e Itália (24\%), além da vertiginosa ascensão do número percebido na Espanha (42\%), em um período em que houve declínio na França $(-2,15 \%)$ e no Reino Unido (-2,23\%) e aumento na Alemanha $(2,11 \%)$ - países com maior número histórico de publicações na União Europeia.

A partir de 2008, a Alemanha aponta um crescimento tímido, mas consistente em seu número de publicações, principalmente quando comparado até 2010 com o Reino Unido, país com maior número de publicações. Embora os $6,32 \%$ de acréscimo, quando comparados os anos de 2000 a 2011, possam parecer pequenos frente a Holanda, Espanha e Itália, este número conferiu ao país o posto de número um na União Europeia em 2011.

Levando em consideração os dados da Unesco Institute for Statistics, o número de pesquisadores em universidades alemãs aumentou 25,7\% no período de 2008 a 2011, enquanto que de 2000 a 2007 o aumentou foi da ordem de $8,8 \%{ }^{16}$. Embora seja difícil mensurar exatamente quanto desse crescimento se deveu ao planejamento do governo federal, um efeito positivo nesse número parece plausível, principalmente ao se considerar a taxa de natalidade do país ${ }^{17}$.

\section{Conclusão}

A mobilidade estudantil no século XXI passou a abranger questões que vão muito além dos muros das universidades. Em certo sentido, esse movimento é tido como um processo de transferência de conhecimento ou cooperação

15- Dos países que aderiram à União Europeia em 2004, apenas a Polônia detinha 43\% das publicações, com 6.600.

17 - Refere-se à série Researchers (FTE) - Higher education. Quantidade de pesquisadores dedicados em tempo integral em universidades alemãs: 2000 - 67.087; 2007 - 72.985; 2008 - 76.831; e 2012 - 96.600.

17- Segundo dados do Banco Mundial, a população do país apresentou um decréscimo de 2,34\% entre 2000 e 2011. científica entre países, motivo pelo qual tal agenda passou a fazer parte das políticas governamentais. Especificamente no caso da Alemanha, o país, por ser extremamente dependente de sua indústria para exportação, depende também da ciência gerada nas universidades para a manutenção de sua competitividade para que, caso não possa ser a ponta-de-lança na geração de novas tecnologias, possa ao menos não perder de vista as inovações produzidas pelas lideranças nos campos científico e tecnológico.

Os dados disponíveis para a maioria das séries até 2011 não são conclusivos, pois, como se viu, o resultado gerado pelas universidades no desenvolvimento de novas tecnologias muitas vezes demanda um relacionamento de longo prazo. Além disso, a cooperação científıca pode se tornar uma faca de dois gumes para o movimento de absorção de conhecimentos. Vale a afirmação de Maringe (2010), segundo a qual "há sempre alguém no controle", e, conforme sublinha Taylor (2010), se as políticas nacionais de todos os países envolvidos no processo de intercâmbio científico não forem suficientes para equacionar a problemática do brain drain por meio do brain circulation, a necessidade de atuação dos organismos internacionais será imperativa.

Nessa mesma medida, no que tange à apropriação de pesquisadores e estudantes estrangeiros, pode-se dizer que tal artifício, em certo sentido, já foi utilizado pela Alemanha nos tempos de seu milagre econômico, período no qual a economia do país experimentou crescimento abundante depois da Segunda Guerra Mundial. À época, a economia alemã crescia a taxas altíssimas, e a falta de mão de obra representava um problema para a manutenção do crescimento. Mas, como resultado, após a reversão da situação com a forte participação de mão de obra imigrante temporária e com a instalação da estagflação, esses trabalhadores tiveram de voltar para seus países, sem nenhum poder de decisão.

Assim, a mobilidade estudantil na Alemanha é um problema relevante e se reveste 
da maior importância para o estudo da cooperação internacional nos dias atuais. Considerando sua condição de liderança econômica e política, após uma história repleta de rupturas, ao buscar manter seu desenvolvimento, o país cria um sistema institucional de cooperação organizado pelo Estado, visando a indústria e operado pela universidade, envolvendo atores externos, que apresenta possibilidades de ganhos generalizados, merecendo, portanto, um estudo detalhado.

\section{Referências}

ABRAMOVSKY, Laura; HARRISON, Rupert; SIMPSON, Helen. University research and the location of business R\&D. IFS Working Papers, London, n. 07/02, Aug. 2006.

BR00KS, Rachel, WATERS, Johanna. Student mobilities, migration and the internalization of higher education. Hampshire: Palgrave Macmillan, 2011.

BUNDESMINISTERIUM FÜR BILDUNG UND FORSCHUNG. Ausländische studierende in Deutschland 2012: Ergebnisse der 20. Sozialerhebung des Deutschen Studentenwerk durschgeführt vom Deutschen Zentrum für Hochschul - und Wissenchaftsforschung (DZHW), 2012.

BUNDESMINISTERIUM FÜR BILDUNG UND FORSCHUNG. Strategy of the federal government for the internationalization of science and research. Feb. 2008.

EDQUIST, Charles. The systems of innovation approach and innovation policy: an account of the state of art. In: DRUID SOCIETY CONFERENCE, 2011, Begin. Druid... Copenhagen: National System of Innovation: Institutions and Public Policies, 2011.

FRITSCH, Michal; SLAVTCHEV, Viktor. Universities and innovation in space. Freiberg Working Paper, n. 15, 2006. Fakultät für Wirtschaftswissenschaften.

GLASSMAN, Ulrich. Rule-breaking and freedom of rules in national production models: how German capitalism departs from the 'rhenish equilibrium' In: CROUCH, Colin; VOELZKOW, Helmut (Org.). Innovation in local economies: Germany in comparative context. New York: Oxford University Press, 2009.

GROSSMAN Gene M., HELPMAN, Elhanan. Growth and welfare in a small open economy. NBER Working Paper Series, Cambridge, n. 2970, July 1989.

HÜBNER, Kurt. Innovationssysteme und „varieties of capitalism“ unter bedingungen ökonomischer globalisierung. In: BLÄTTELMINK, Birgit; EBNER, Alexander (Org.). Innovationssysteme: technologie, institutionen und die dynamik der wettbewerbsfähigkeit. Köln: VS Verlag für Sozialwissenschaften, 2009. p. 143-157.

LANGE, Henning. Forschungskooperationen zwischen Universitäten und Industrie: Kooperationsentscheidung und Performance Management. Augsburg: Springer Gabler, 2013.

LUNDVALL, Bengt-Åke. National innovation system: analytical focusing device and policy learning tool. Working Paper, n. 4, May 2007. Swedish Institute for Growth Policy Studies.

MANSFIELD, Edwin. Academic research underlying industrial innovations: sources, characteristics and financing. The Review of Economics and Statistics, v. 77, n. 1, p. 55-65, Feb. 1995).

MARINGE, Felix. The meanings of globalization and internationalization in HE: findings from a world survey. In: MARINGE, Felix; FOSKETT, Nick (Org.). Globalization and internationalization in higher education: theoretical, strategic and management perspectives. London: Continuum International Publishing Group, 2010.

MARLOW-FERGUSON, Rebecca (Ed.). World education encyclopedia: a survey of educational systems worldwide. v. 1. 2. ed. Farmington Hills: Gale Group, 2002. 
NATIONAL ACADEMY OF SCIENCES. The impact of academic research on industrial performance. Washington, D.C.: National Academy Press, 2011.

NELSON, Richard R.; ROSENBERG, Nathan. Technical innovation and national systems. In: NELSON, Richard R. (Org.). National innovation systems: a comparative analysis. New York: Oxford University Press, 1993.

OECD - ORGANISATION FOR ECONOMIC CO-OPERATION AND DEVELOPMENT. National innovation systems. Paris: OECD, 1997. OECD - ORGANISATION FOR ECONOMIC CO-OPERATION AND DEVELOPMENT. Internationalization and trade in higher education: opportunities and challenges. Paris: OECD, 2002.

OZTURK, Ilhan. The role of education in economic development: a theoretical perspective. MPRA Paper, Munique, n. 9023, June 2001. Munich Personal RePEc Archive.

RACY, Joaquim C. Política externa brasileira: cooperação e desenvolvimento na primeira metade da década de 1990. 2007. 246 f. Tese (Doutorado em História) - Pontifícia Universidade Católica de São Paulo (PUC-SP), São Paulo, 2007.

STOKES, Donald E. Pasteur's quadrant: basic Science and technological innovation. Washington, D.C.: Brookings Institution Press, 1997.

TAYLOR, John. The response of governments and universities to globalization and internalization in higher education. In: MARINGE, Felix; FOSKETT, Nick (Org.). Globalization and internationalization in higher education: theoretical, strategic and management perspectives. London: Continuum International Publishing Group, 2010. p. 83-96.

THURSBY, Emory; THURSBY, Marie. Here or there: a survey of factors in multnational R\&D location. Washington, D.C.: National Academy Press, 2006.

WIXTED, Brian. Innovation system frontiers: cluster networks and global value. Heidelberg : Springer-Verlag, 2009.

Recebido em: 20.02.2015

Aprovado em: 20.10.2015

Joaquim Carlos Racy é professor dos cursos de economia da Pontifícia Universidade Católica de São Paulo (PUC-SP) e da Universidade Presbiteriana Mackenzie (UPM). É professor do Programa de Estudos Pós-Graduados em Economia Política da PUC-SP, pesquisador do Núcleo de Análise da Conjuntura Internacional (NACl) da PUC-SP e coordenador do Núcleo de Acompanhamento da Economia Contemporânea (NAEC) da UPM.

Everton de Almeida Silva é mestrando em economia pelo Programa de Estudos Pós-Graduados em Economia Política da PUC-SP e pesquisador do NACl da PUC-SP. 